Internist 2018 $59: 871-872$

https://doi.org/10.1007/s00108-018-0448-8

Online publiziert:4. Juni 2018

(c) Springer Medizin Verlag $\mathrm{GmbH}$, ein Teil von Springer Nature 2018

CrossMark

H. Woehrle $\cdot$ 0. Oldenburg ${ }^{2,3} \cdot$ S. Stadler ${ }^{4} \cdot$ M. Arzt $^{4}$

'Schlaf- und Beatmungszentrum Blaubeuren, Lungenzentrum Ulm, Ulm, Deutschland

${ }^{2}$ Klinik für Kardiologie, Herz- und Diabeteszentrum NRW, Universitätsklinik der Ruhr-Universität Bochum, Bad Oeynhausen, Deutschland

${ }^{3}$ Ludgerus-Kliniken, Clemenshospital, Lehrkrankenhaus der Westfälischen Wilhelms-Universität, Münster, Deutschland

${ }^{4}$ Schlafmedizinisches Zentrum, Klinik und Poliklinik für Innere Medizin II, Universitätsklinikum Regensburg, Regensburg, Deutschland

\title{
Erratum zu: Schlafapnoe als Komorbidität bei Herzinsuffizienz
}

\section{Erratum zu:}

Internist 2018

https://doi.org/10.1007/s00108-018-

0412-7

In diesem Beitrag ist ein Fehler in $\bullet$ Abb. 1 aufgetreten. In Teilabbildung $b$ wurde die Beschriftung der verschiedenen Kanäle vertauscht. Die Redaktion bittet den Fehler zu entschuldigen und um die Beachtung der korrekten Darstellung.

\section{Korrespondenzadresse}

Prof. Dr. M. Arzt

Schlafmedizinisches Zentrum, Klinik und Poliklinik für Innere Medizin II, Universitätsklinikum Regensburg

Franz-Josef-Strauß-Allee 11, 93053 Regensburg, Deutschland

michael.arzt@klinik.uni-regensburg.de

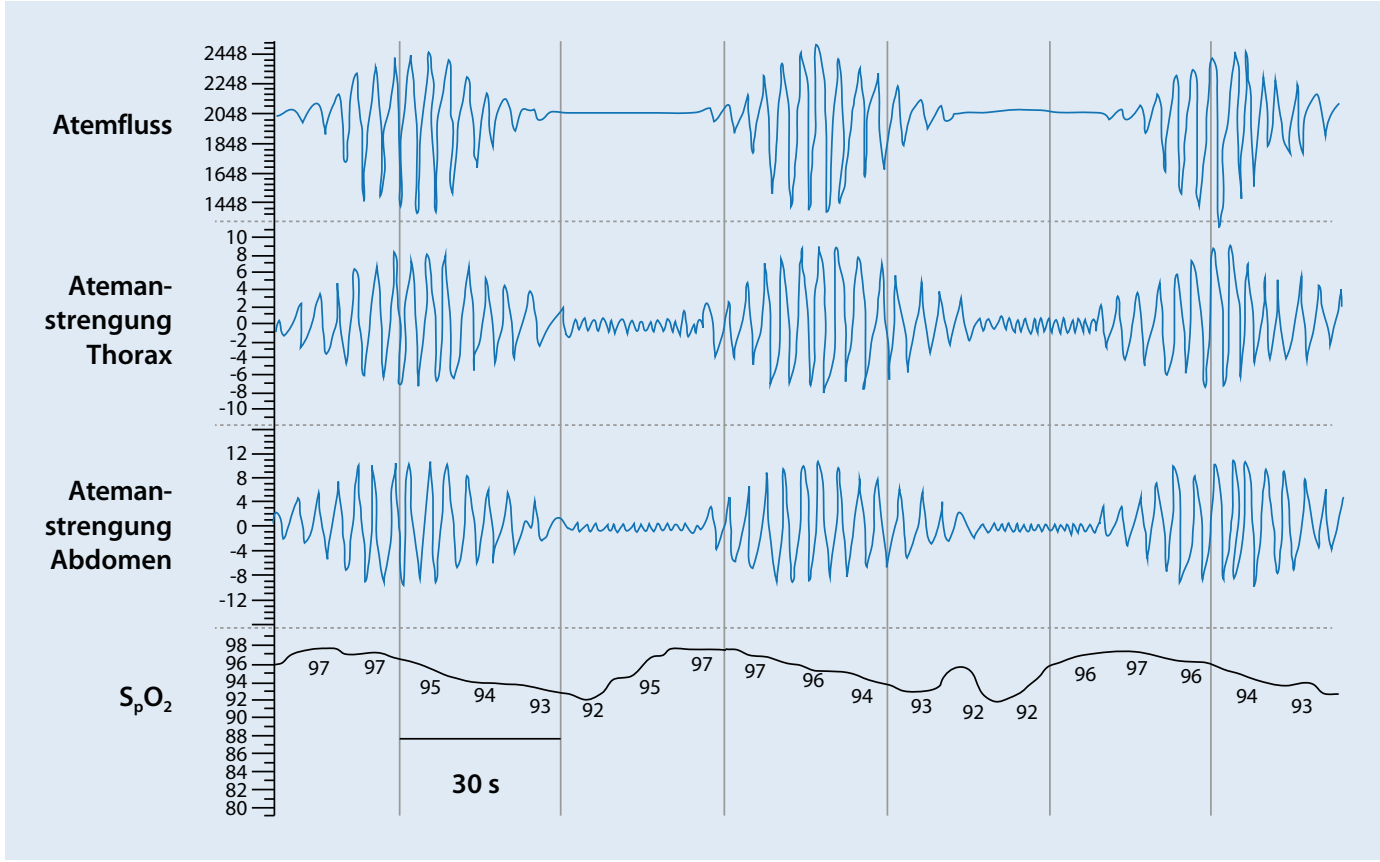

Abb. 1b 4 Ausschnitte einer polysomnographischen Aufzeichnung mit den ausgewählten Kanälen Atemfluss, Atemanstrengungen des Thorax und des Abdomens sowie pulsoxymetrisch gemessene Sauerstoffsättigung $\left(\mathrm{S}_{\mathrm{p}} \mathrm{O}_{2}\right)$. 2 zentrale Apnoen 
Hier steht eine Anzeige.

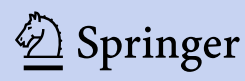

